\title{
VISIBLE LIGHT INDUCED PHOTOCATALYTIC DEGRADATION OF SOME XANTHENE DYES USING IMMOBILIZED ANTHRACENE
}

\author{
Pinki B. Punjabi*, Rakshit Ameta, Anil Kumar ${ }^{*}$ and Madhu Jain \\ Solar Energy and Photochemistry Laboratory, Department of Chemistry, University College of \\ Science, M. L. Sukhadia University, Udaipur - 313002, (Rajasthan) India
}

(Received October 24, 2007; revised February 4, 2008)

\begin{abstract}
Photocatalytic degradation of eosin and erythrosin-B (xanthene dyes) has been carried out using anthracene semiconductor immobilized on polyethylene films. Effect of various parameters like $\mathrm{pH}$, concentration of dyes, amount of semiconductor and light intensity have been studied on the rate of reaction. Various control experiments were carried out which indicated that semiconductor anthracene played a key role in photocatalytic degradation of dyes. A suitable tentative mechanism has been proposed for photocatalytic degradation of dyes.
\end{abstract}

KEY WORDS: Photocatalytic, Degradation, Xanthene dyes, Immobilized anthracene

\section{INTRODUCTION}

Dye pollutants from the textile industries play a very important role in contaminating the environment. Environmental pollution by the wastewater containing dyes is setting an ecological problem and hazards to aquatic animals. About $15 \%$ of the total world production of the dyes is lost during the dyeing process [1].

Recently, heterogeneous photochemical processes using semiconductor as a photocatalyst have gained wide interest in treatment of effluents from textile industries [2-6]. In this process, semiconductor particles are irradiated with light energy equal to or greater than its band gap. It results in the formation of electron-hole pair. Electron is present in conduction band, whereas hole is present in the valence band. The field of photocatalysis has been extensively reviewed by many researchers [7, 8]. Punjabi et al. [9] studied the photoreduction of congo red by ascorbic acid and EDTA as reductants over cadmium sulfide as a photocatalyst. The photodegradation of dye pollutants on silica gel supported $\mathrm{TiO}_{2}$ particles under visible light has been studied by Chen et al. [10]. Photocatalytic degradation of a textile azo dye (Sirius Gelb) on $\mathrm{TiO}_{2}$ or $\mathrm{Ag}^{-\mathrm{TiO}_{2}}$ particles in the absence and presence of UV radiations has been reported by Ozkan et al. [11].

In the present investigation, the semiconducting properties of a readily available substance anthracene in colloidal form will be utilized for photocatalytic degradation of some xanthene dyes. Like other inorganic semiconductor photocatalysts, anthracene colloid also acts as an organic semiconductor. It absorbs photons to create electron - hole pair, which can participate in the redox reactions further. Since colloidal anthracene remains in form of suspension and creates a problem in the measurement of absorbance. Therefore, to avoid this problem an attempt has been made to immobilize colloidal anthracene on polyethylene films. The immobilized anthracene has been used for the photocatalytic degradation of dyes.

\section{EXPERIMENTAL}

Material and methods

Eosin (BDH, UK), erythrosin-B (CDH, India), anthracene (BDH, UK), glacial acetic acid $(\mathrm{BDH}, \mathrm{UK})$ and araldite (India) were of laboratory grade and were used as received. In all experiments aqueous solutions of the dyes (usually $10^{-5} \mathrm{M}$ at $\mathrm{pH} \approx 7$ ) were prepared.

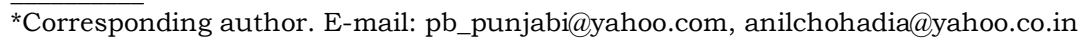


For $\mathrm{pH}$ measurement a digital $\mathrm{pH}$ meter (Systronics Model 324, India) was used. A $200 \mathrm{~W}$ tungsten lamp (Phillips, India) was used for irradiating the reaction mixture in visible range. The light intensity was measured with the help of a solarimeter (Surya Mapi Model CEL 201, India).

The progress of the reaction was followed spectrophotometrically by measuring the absorbance of the reaction mixture at their respective $\lambda_{\max }$ values at different time intervals. A spectrophotometer (Systronics Model 106, India) was used for measuring the absorbance of the reaction mixture.

\section{Preparation of anthracene colloid and its mmobilization on polyethylene films}

Anthracene colloidal suspension was prepared by dissolving $100.0 \mathrm{mg}$ anthracene in $1.0 \mathrm{~mL}$ of warm glacial acetic acid. When this solution was poured into water, a milky white colloidal suspension of anthracene was formed. The colloidal suspension of anthracene was washed with water several times and then dried in an oven.

It was observed that the use of semiconductor colloidal anthracene creates problem in correct measurement of absorbance because it remains in the form of suspension. Therefore, an attempt was made to immobilize the colloidal anthracene on polyethylene films. Circular polyethylene films were cleaned and coated with araldite (insoluble in water). Then colloidal anthracene powder was spread evenly on the surface of polyethylene films. After air-drying the films were washed with water to release loosely bound particles of colloidal anthracene and films were dried at room temperature.

\section{Photocatalytic degradation of dyes}

For each observation $50.0 \mathrm{~mL}$ of dye solution $\left(\approx 10^{-5} \mathrm{M}\right)$ was taken in a reaction flask and 0.04 $\mathrm{g}$ of semiconductor anthracene (immobilized on polyethylene films) was added to it. The infrared fraction of light was eliminated by keeping a water filter between irradiation source and reaction mixture. The pre-aerated reaction mixture was exposed to tungsten lamp. Absorbance of the reaction mixture was observed at regular time intervals.

In a control experiment, photocatalytic degradation was carried out in the presence of nonconducting alumina $\left(\mathrm{Al}_{2} \mathrm{O}_{3}\right)$ in place of anthracene. It was observed that there was no appreciable photodegradation of dyes in presence of alumina, indicating that for photodegradation of dyes semiconductor anthracene plays a key role.

In another control experiment, equal quantities of dye solution were taken in four beakers (50.0 $\mathrm{mL}$ dye solution in each). The first beaker containing dye solution was kept in dark, whereas the second beaker containing only dye solution was kept in sunlight. $0.04 \mathrm{~g}$ of semiconductor anthracene (immobilized on polyethylene film) was added to the third beaker containing dye solution and it was kept in dark, and $0.04 \mathrm{~g}$ of semiconductor anthracene (immobilized on polyethylene film) was added to the beaker containing dye solution and was exposed to sunlight.

These beakers were kept for four hours and absorbance of the solution in each beaker was measured by spectrophotometer. It was observed that the solutions of the first three beakers had the same initial absorbance while the solution of the fourth beaker had a decrease in its initial value of absorbance. The above experiment confirms that the reaction between dye and semiconductor anthracene is neither thermal nor photochemical but it is a photocatalytic reaction. 


\section{RESULTS AND DISCUSSION}<smiles>NC(=O)c1ccccc1-c1c2cc(Br)c(=O)c(Br)c-2oc2c(Br)c(O[Na])c(Br)cc12</smiles>

Eosin dye

$\lambda_{\max }=515 \mathrm{~nm}$<smiles>COc1c(I)cc2c(-c3ccccc3C(N)=O)c3cc(I)c(=O)c(I)c-3oc2c1I</smiles>

Erythrosin-B dye $\lambda_{\max }=525 \mathrm{~nm}$

The structure and $\lambda_{\max }$ of eosin and erythrosin-B are shown above. By variation of different parameters like $\mathrm{pH}$, dye concentration, amount of semiconductor and light intensity optimum conditions were obtained for photocatalytic degradation of each dye at their respective $\lambda_{\max }$ values. Typical runs were obtained by plotting $1+\log$ A vs time. These plots were found linear indicating that photocatalytic degradation of dyes follow pseudo first order kinetics. The rate constant (k) was determined using following expression,

$$
\mathrm{k}=2.303 \times \text { slope }
$$

For both dyes typical run data are presented in Table 1 and graphically in Figure 1.

Table 1. Typical run for eosin and erythrosine.

\begin{tabular}{|c|c|c|}
\hline \multirow{2}{*}{$\begin{array}{c}\text { Time of irradiation } \\
(\mathrm{min})\end{array}$} & \multicolumn{2}{|c|}{$1+\log \mathrm{A}$} \\
\cline { 2 - 3 } & Eosin & Erythrosin-B \\
\hline 0.0 & 0.960 & 1.041 \\
\hline 15.0 & 0.952 & 0.997 \\
\hline 30.0 & 0.942 & 0.923 \\
\hline 45.0 & 0.932 & 0.855 \\
\hline 60.0 & 0.924 & 0.790 \\
\hline 75.0 & 0.914 & 0.721 \\
\hline 90.0 & 0.905 & 0.650 \\
\hline 105.0 & 0.896 & 0.588 \\
\hline 120.0 & 0.886 & 0.517 \\
\hline 135.0 & 0.878 & 0.455 \\
\hline 150.0 & 0.869 & 0.382 \\
\hline & $\mathrm{k}=2.31 \pm 0.058 \times 10^{-5} \mathrm{~s}^{-1}$ & $\mathrm{k}=1.75 \pm 0.044 \times 10^{-4} \mathrm{~s}^{-1}$ \\
\hline
\end{tabular}

$[$ Eosin $]=7.50 \times 10^{-6} \mathrm{M}, \mathrm{pH}=8.0$, anthracene $=0.04 \mathrm{~g}$, light intensity $=40.0 \mathrm{mWcm}^{-2}$.

$\left[\right.$ Erythrosin-B] $=1.00 \times 10^{-5} \mathrm{M}, \mathrm{pH}=8.0$, anthracene $=0.04 \mathrm{~g}$, light intensity $=40.0 \mathrm{mWcm}^{-2}$.

It was observed that the rate of reaction was slightly higher if colloidal anthracene is used but a part of anthracene will be lost along with effluent. Therefore, the immobilized anthracene was used throughout the present investigation. 


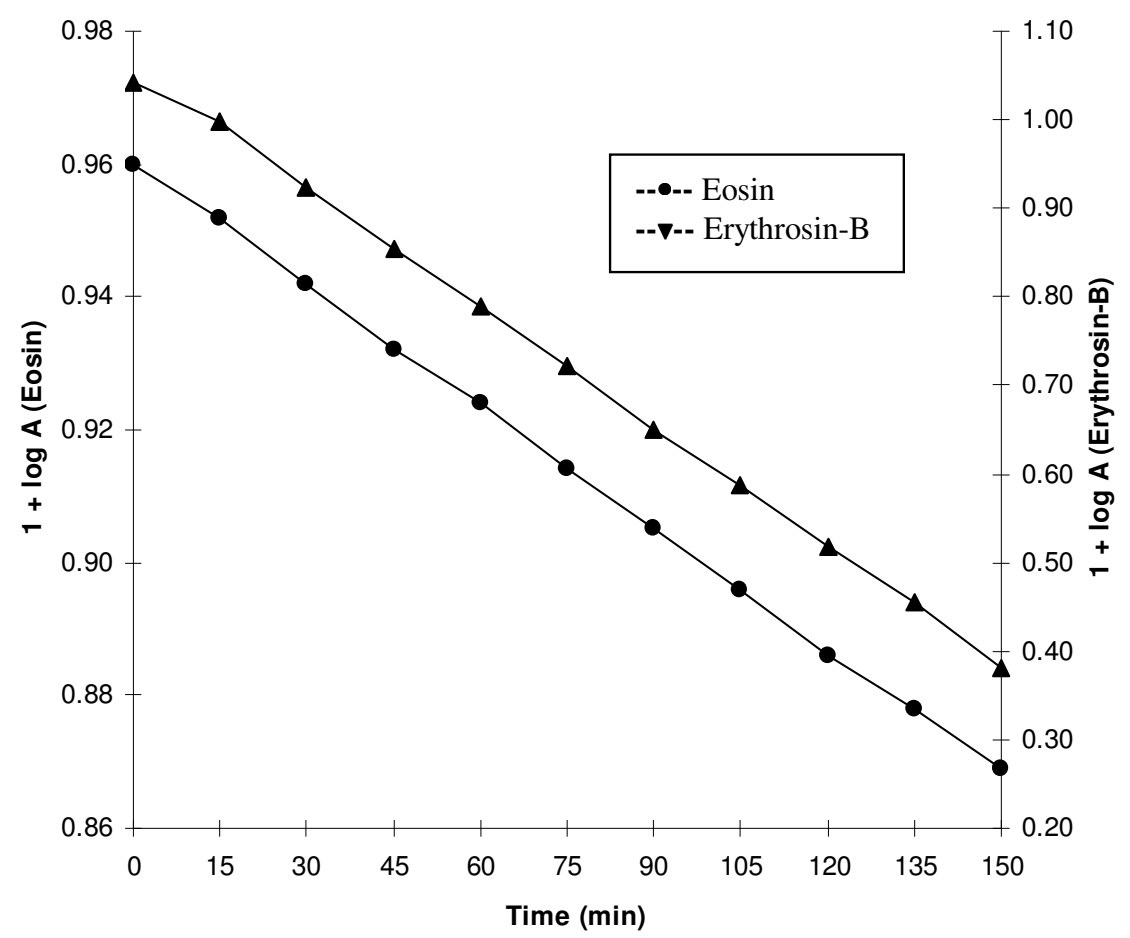

Figure 1. Typical run: $[$ eosin $]=7.50 \times 10^{-6} \mathrm{M}, \mathrm{pH}=8.0$, anthracene $=0.04 \mathrm{~g}$, light intensity $=$ $40.0 \mathrm{mWcm}^{-2} ;$ [erythrosin-B] $=1.00 \times 10^{-5} \mathrm{M}, \mathrm{pH}=8.0$, anthracene $=0.04 \mathrm{~g}$, light intensity $=40.0 \mathrm{mWcm}^{-2}$.

\section{Effect of $p H$}

The influence of the $\mathrm{pH}$ on the rate of photocatalytic bleaching for both dyes is shown in Figure 2. The degradation curves for dyes have been plotted between rate constant and corresponding $\mathrm{pH}$ values. The results show that photocatalytic bleaching of the dyes is strongly dependent on the $\mathrm{pH}$ of the solution. A weakly alkaline $\mathrm{pH}$ was found to be favorable for photocatalytic degradation of dyes. Photocatalytic degradation was studied in the $\mathrm{pH}$ range 6.0-10.0.

It was observed that rate of reaction increases on increasing the $\mathrm{pH}$, and after a certain $\mathrm{pH}$, further increase in $\mathrm{pH}$ decreases the rate of reaction. Initially, when the $\mathrm{pH}$ is slightly acidic the rate increases due to availability of $\mathrm{OH}^{-}$ions in a concentration which is required for increasing the rate of reaction. These $\mathrm{OH}^{-}$ions generate ${ }^{\circ} \mathrm{OH}$ radicals which are effective oxidizing species and responsible for photocatalytic degradation of dyes. As the $\mathrm{pH}$ of the reaction mixture was further increased (alkaline $\mathrm{pH}$ ) more $\mathrm{OH}^{-}$ions are introduced in the reaction mixture, which make the surface of the semiconductor negatively charged. Repulsive forces start interacting between the negatively charged semiconductor surface and dye anions, thereby making the approach of dye anions on the surface of semiconductor difficult. It results in the decrease in rate of photocatalytic bleaching of dyes (Figure 2). 


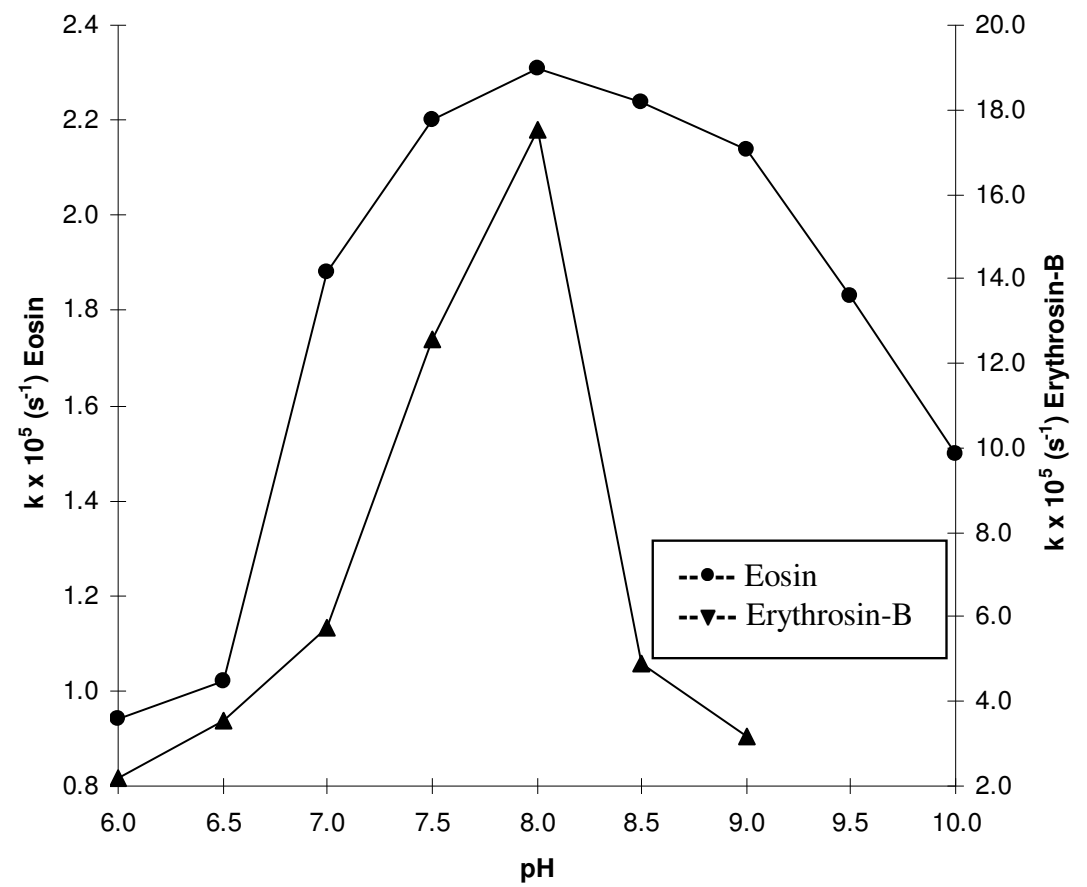

Figure 2. Effect of $\mathrm{pH}$ : $\left[\right.$ eosin] $=7.50 \times 10^{-6} \mathrm{M}$, anthracene $=0.04 \mathrm{~g}$, light intensity $=40.0$ $\mathrm{mWcm}^{-2} ;$ [erythrosin-B] $=1.00 \times 10^{-5} \mathrm{M}$, anthracene $=0.04 \mathrm{~g}$, light intensity $=40.0$ $\mathrm{mWcm}^{-2}$.

\section{Effect of concentration of dyes}

Photocatalytic bleaching increases with increase in the concentration of dyes. It may be attributed to the fact that as the concentration of the dye was increased, more dye molecules were available for excitation and energy transfer, resulting in an increase in rate of reaction. But beyond a certain concentration, an increase in concentration of dyes adversely affected the reaction rate. This is because at higher concentration dyes starts acting as a blanket or cover and will not permit the desired light intensity to reach the semiconductor surface, thus decreasing the rate of photocatalytic bleaching (Figure 3). Photocatalytic degradation was studied in the concentration range $0.25 \times 10^{-5} \mathrm{M}$ to $2.25 \times 10^{-5} \mathrm{M}$.

\section{Effect of amount of semiconductor}

It was observed that rate of photocatalytic bleaching of dyes increase with an increase in the amount of the semiconductor. But after certain fixed concentration of semiconductor the rate becomes almost constant because higher concentration of semiconductor increases only thickness and not the surface area. Thus the active sites on semiconductor surface become constant at higher concentration, and therefore the rate too (Figure 4). The photocatalytic degradation of eosin and erythrosin-B was studied in the range $0.010 \mathrm{~g}$ to $0.060 \mathrm{~g}$. 


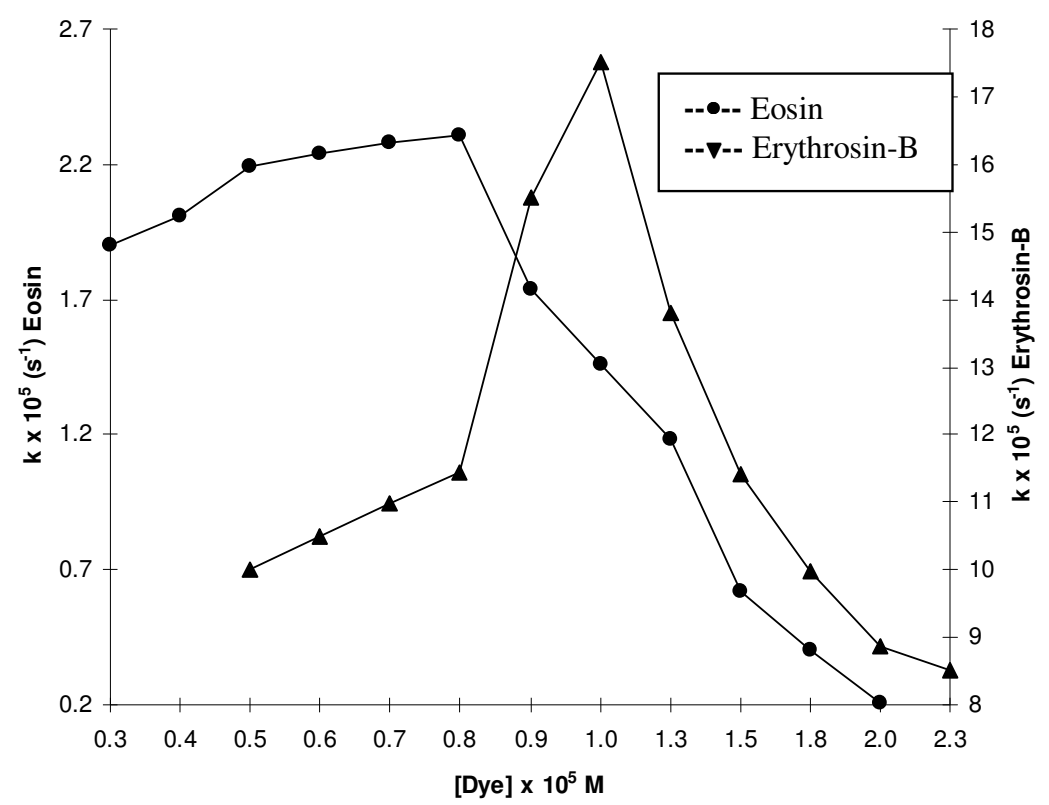

Figure 3. Effect of dye concentration: for both dyes $\mathrm{pH}=8.0$, anthracene $=0.04 \mathrm{~g}$, light intensity $=40.0 \mathrm{mWcm}^{-2}$.

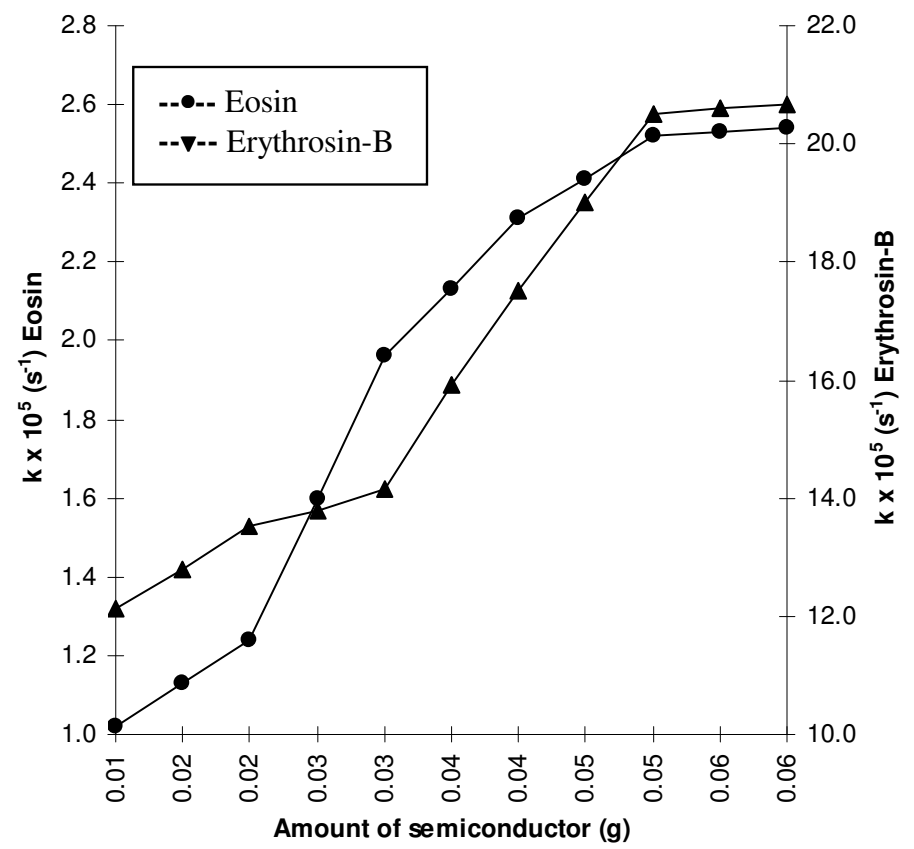

Figure 4. Effect of amount of semiconductor: $[$ eosin $]=7.50 \times 10^{-6} \mathrm{M}$, [erythrosin-B] $=1.00 \mathrm{x}$ $10^{-5} \mathrm{M}$, for both dyes $\mathrm{pH}=8.0$, light intensity $=40.0 \mathrm{mWcm}^{-2}$. 


\section{Effect of light intensity}

An increase in the light intensity accelerated the rate of the reaction because any increase in the light intensity will increase the number of photons striking per unit area of semiconductor powder (Figure 5). The photocatalytic degradation of eosin and erythrosin-B was studied in the range $20.0-70.0 \mathrm{mWcm}^{-2}$.

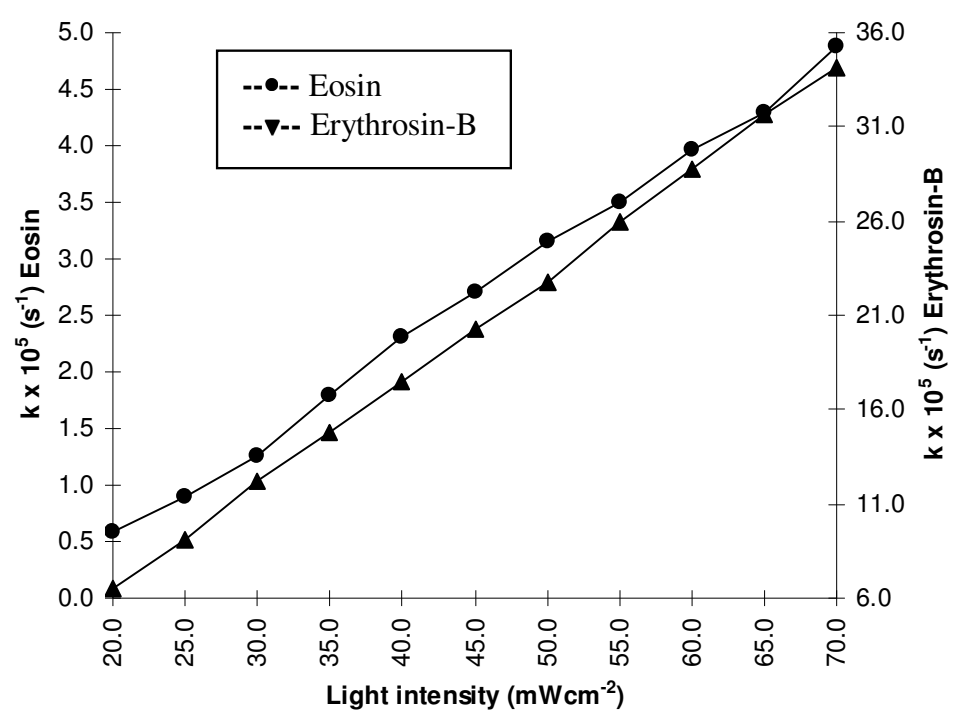

Figure 5. Effect of light intensity: $\left[\right.$ eosin] $=7.50 \times 10^{-6} \mathrm{M}, \mathrm{pH}=8.0$, anthracene $=0.04 \mathrm{~g}$; [erythrosin- $\mathrm{B}]=1.00 \times 10^{-5} \mathrm{M}, \mathrm{pH}=8.0$, anthracene $=0.04 \mathrm{~g}$.

\section{Mechanism}

On the basis of the above findings following tentative mechanism for the photocatalytic degradation of dyes has been proposed.

The reaction is initiated by the photoexcitation of ground state dye molecules to their excited singlet state which then undergo intersystem crossing to their triplet state.

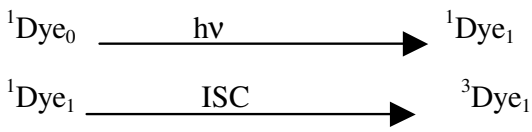

Semiconductor anthracene $[12,13]$ also gets photoexcited leading to the formation of electron hole pairs.

$$
\text { Anthracene }\left(\mathrm{C}_{14} \mathrm{H}_{10}\right) \longrightarrow \mathrm{C}_{14} \mathrm{H}_{10}\left(\mathrm{e}_{\mathrm{CB}}{ }^{-}+\mathrm{h}_{\mathrm{VB}}{ }^{+}\right)
$$

The photogenerated hole $\left(\mathrm{h}^{+}\right)$abstracts an electron from the triplet dye leading to the formation of dye cation $\left(\mathrm{Dye}^{+}\right.$) which reacts with $\mathrm{OH}^{-}$ions giving ${ }^{\circ} \mathrm{OH}$ radicals, the actual oxidizing agents.

$$
{ }^{3} \mathrm{Dye}_{1}+\mathrm{h}^{+} \text {(anthracene) } \longrightarrow \mathrm{Dye}^{+}+\mathrm{C}_{14} \mathrm{H}_{10}\left(\mathrm{e}_{\mathrm{CB}}{ }^{-}\right)
$$




$$
\mathrm{Dye}^{+}+\mathrm{OH}^{-} \longrightarrow \mathrm{Dye}+{ }^{\cdot} \mathrm{OH}
$$

Electrons $\left(\mathrm{e}_{\mathrm{CB}}{ }^{-}\right)$are removed by the dissolved molecular oxygen to produce superoxide anion radicals which then react with water to form more and more ${ }^{\circ} \mathrm{OH}$ radicals. The semiconductor anthracene is regenerated for further reaction.

$$
\begin{aligned}
& \mathrm{C}_{14} \mathrm{H}_{10}\left(\mathrm{e}_{\mathrm{CB}}^{-}\right)+\mathrm{O}_{2} \longrightarrow \mathrm{C}_{14} \mathrm{H}_{10}+\mathrm{O}_{2}^{{ }^{-}} \\
& \mathrm{O}_{2}^{{ }^{-}}+2 \mathrm{H}_{2} \mathrm{O} \longrightarrow 2 \cdot \mathrm{OH}+2 \mathrm{OH}^{-}+\mathrm{O}_{2}
\end{aligned}
$$

The reaction of $\mathrm{OH}$ radicals with dye molecules leads to its oxidation into colourless gaseous products.

$$
\text { Dye }+{ }^{\circ} \mathrm{OH} \longrightarrow \text { Colourless gaseous products }
$$

The participation of $\cdot \mathrm{OH}$ radicals in the reaction was confirmed by the use of electron acceptor like hydrogen peroxide, $\mathrm{H}_{2} \mathrm{O}_{2}$ in the reaction mixture. The $\mathrm{H}_{2} \mathrm{O}_{2}$ reacts with $\mathrm{e}_{\mathrm{CB}}{ }^{-}$to produce ${ }^{\circ} \mathrm{OH}$ radicals, which accelerate the rate of the dye degradation.

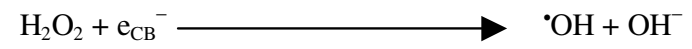

\section{AKNOWLEDGEMENTS}

We are highly thankful to Prof. Suresh C. Ameta, Department of Chemistry, M. L. Sukhadia University, Udaipur (Rajasthan, India) for valuable critical discussions.

\section{REFERENCES}

1. Zollinger, H. (Ed.) Color Chemistry, Synthesis, Properties and Applications of Organic Dyes and Pigments, 2nd ed., VCH: Weinheim; 1991.

2. Konatantinou, I.; Sakellarides, T.M.; Sakkas, V.; Albanis, T.A. Environ. Sci. Technol. 2001, 35, 398.

3. Matthews, R.W. J. Catal. 1988, 111, 264.

4. Grzechulska, J.; Hamerski, M.; Morawski, A.W. Wat. Res. 2000, 34, 1638.

5. Mas, D.; Pichat, P.; Guillard, C. Res. Chem. Intermed. 1997, 23, 275.

6. Osora, H.; Li, W.; Otero, L.; Fox, M.A. J. Photochem. Photobiol. B 1998, 43, 232.

7. Ameta, S.C.; Choudhary, R.; Ameta, R.; Vardia, J. J. Ind. Chem. Soc. 2003, 80, 257.

8. Scheavello, M. Heterogeneous Photocatalysis, Wiley: New York; 1997.

9. Punjabi, P.B.; Ameta, R.; Vyas, R.; Kothari, S. Ind. J. Chem. 2005, 44A, 2266.

10. Chen, Y.X.; Wany, K.; Louep, J. Photochem. Photobiol. A 2004, 163, 281.

11. Ozkan, A.; Ozkan, M.H.; Gurkan, R.; Akay, M.; Sokmen, M. J. Photochem. Photobiol. A 2004, 163, 29.

12. Meicr, H. Organic Semiconductors, Dark and Photoconductivity Organic Solids, Verlag Chemisorb: Weinhein; 1974.

13. Gutmann, F.; Lyons, L.F. Organic Semiconductors, Wiley: New York; 1967. 